Original research article

\title{
Chokeberry juice supplementation in type 2 diabetic patients - impact on health status
}

\author{
Milica Milutinović ${ }^{1}$, Radmila Veličković Radovanović ${ }^{2,3}$, Katarina Šavikin ${ }^{4}$, Saša Radenković ${ }^{5,6}$, \\ Marjan Arvandi ${ }^{7}$, Milica Pešić ${ }^{5,6}$, Milica Kostić ${ }^{1}$, Bojana Miladinović ${ }^{1}$, Suzana Branković ${ }^{8}$, \\ Dušanka Kitić ${ }^{1 *}$ \\ ${ }^{1}$ University of Niš, Faculty of Medicine, Department of Pharmacy, Niš, Serbia \\ ${ }^{2}$ University of Niš, Faculty of Medicine, Department of Pharmacology, Niš, Serbia \\ ${ }^{3}$ Clinical Center Niš, Clinic of Nephrology, Niš, Serbia \\ ${ }^{4}$ Institute for Medicinal Plants Research "Dr. Josif Pančić", Belgrade, Serbia \\ ${ }^{5}$ University of Niš, Faculty of Medicine, Department of Internal Medicine, Niš, Serbia \\ ${ }^{6}$ Clinical Center Niš, Clinic of Endocrinology, Diabetes and Metabolic Disorders, Niš, Serbia \\ ${ }^{7}$ Institute of Public Health, Medical Decision Making, and Health Technology Assessment, UMIT, Hall in Tirol, Austria \\ ${ }^{8}$ University of Niš, Faculty of Medicine, Department of Physiology, Niš, Serbia
}

\begin{abstract}
Recent literature evidence indicates the potential use of chokeberry preparations in the prevention and treatment of some chronic noncommunicable diseases. The aim of the present study was to evaluate the effects of the three months oral chokeberry juice supplementation in type 2 diabetic patients, as well as its influence on hematological parameters and certain parameters of the renal dysfunction. The study was designed as an open-label trial, which included 35 patients who have received the herbal supplement, polyphenol-rich chokeberry juice $(150 \mathrm{ml} /$ day, three times a day for $50 \mathrm{ml})$, in addition to their standard therapy. Chokeberry juice as a rich source of polyphenol compounds could be an effective preventive and therapeutic agent in diabetes mellitus type 2. Hematological and biochemical parameters were measured at baseline, after 3 months with the chokeberry juice supplementation and after the next 3 months without the chokeberry juice supplementation (follow-up period). Significant difference was noticed in the levels of LDL-cholesterol, glycated hemoglobin and serum creatinine $(p<0.05)$, as well as in the levels of some hematological parameters, such as white blood cell and lymphocyte count $(p<0.01)$, hematocrit, blood hemoglobin, mean corpuscular volume, hemoglobin and hemoglobin concentration and red blood cell count $(p<0.05)$. The daily consumption of the chokeberry juice could improve the health status in patients with type 2 diabetes mellitus, in combination with their standard therapy.
\end{abstract}

Keywords: Aronia melanocarpa; Diabetes mellitus type 2; Hematological parameters; Juice; Renal dysfunction

\section{Highlights:}

- Chokeberry juice supplementation improves health in diabetic patients.

- The juice intake improves lipid and glucose metabolism parameters.

- Risk of diabetes complication development is reduced by the juice intake.

- The juice intake improves inflammatory and hematological status in patients.

\section{Introduction}

In recent years, many researchers and scientists from the field of food science and medicine have increasingly recommended the use of various plant products in the prevention and treatment of noncommunicable diseases, such as cardiovascular diseases (heart attacks and stroke), cancers, chronic respiratory diseases (chronic obstructive pulmonary disease and asthma) and diabetes. Literature data show that the use of medicinal plants products and the diet rich in fruits and vegetables could improve the health status in patients, as well as decrease the risk of the disease development (Bloom et al., 2011; Kris-Etherton et al., 2002).
Today, diabetes mellitus (DM) has become a public health care problem of considerable magnitude in many countries. Every year the number of diabetic patients increases so that it is assumed that by 2025, this number reaches at least 300 million (IDF Clinical Guidelines Task Force, 2006). It is necessary to raise awareness of prevention in those people who are at risk of developing the disease, as well as in the whole population in order to reduce the risk factors leading to it. The improvement of the dietary pattern is one of the most important preventive measures which may reduce the incidence of diabetes and also improve the quality of life in diabetic patients (Narayan et al., 2000). Insulin and oral antidiabetic drugs, such as thiazolidinediones, biguanides, $\alpha$-glucosidase inhibitors, and glinides, are the currently available therapy for DM. However, most of

\footnotetext{
* Author for correspondence: Dušanka Kitić, University of Niš, Faculty of Medicine, Department of Pharmacy, Bulevar Zorana Djindjića 81, 18000 Niš, Serbia; e-mail: dkiticyu@yahoo.co.uk http://doi.org/10.32725/jab.2019.020

Submitted: 2018-11-06 • Accepted: 2019-11-04 • Prepublished online: 2019-11-13

J Appl Biomed 17/4: 218-224 • EISSN 1214-0287 • ISSN 1214-021X

(c) 2019 The Authors. Published by University of South Bohemia in České Budějovice, Faculty of Health and Social Sciences.

This is an open access article under the CC BY-NC-ND license.
} 
these drugs have prominent side effects and may increase the risk of diabetic complications. Natural products and food that have beneficial antidiabetic properties could be used as an alternative drug for the prevention of DM, as well as in the early stage of the disease. These alternative drugs have fewer side effects, a lower risk for drug interactions and they simplify therapeutic regimen (Krentz and Bailey, 2005).

Aronia melanocarpa (Michx.) Elliott (black chokeberry, chokeberry, aronia, aronia berry), a woody shrub of the Rosaceae family, has been used in the traditional medicine for centuries worldwide. The interest for the chokeberry and chokeberry's secondary metabolites with a highly expressed antioxidant activity have recently increased mainly due to their health-promoting effects and their possible use in the prevention and treatment of many diseases (Kokotkiewicz et al., 2010; Kulling and Rawel, 2008). Literature data have shown many pharmacological activities of the chokeberry in vivo and in vitro, such as: gastroprotective, hepatoprotective, antidiabetic, anti-inflammatory, antioxidative, antiviral, antimutagenic, anticancer and radioprotective. It has been demonstrated that the chokeberry fruits, extract or juice, have a beneficial effect on several risk factors for cardiovascular disorders, improve the oxidative and lipid status, reduce the level of insulin, reduce the blood pressure in patients with metabolic syndrome, even after a myocardial infarction, and induce normalization of the hemostasis parameters in patients with metabolic syndrome (Borowska and Brzóska, 2016; Sikora et al., 2012; Skoczynska et al., 2007; Valcheva-Kuzmanova et al., 2007a, b).

Therefore, the aim of the present study was to investigate whether three months of oral chokeberry juice supplementation $(150 \mathrm{ml} /$ day, three times a day for $50 \mathrm{ml})$ would induce and sustain the improvement of hyperglycemia, cardiovascular risk factors such as hyperlipidemia, high blood pressure (BP) and body weight, as well as the initial renal dysfunction and blood count in individuals with type 2 diabetes. To the best of our knowledge, the influence of the chokeberry juice supplementation on the hematological parameters and certain parameters of renal dysfunction in type 2 diabetic patients who receive oral antidiabetic drug therapy has not yet been published. Therefore we investigated the effects of the chokeberry juice supplementation on those parameters in addition to other biochemical parameters related to diabetes mellitus type 2 .

\section{Materials and methods}

\section{Patients and study design}

The patients were recruited from the Endocrinology Clinic, Clinical Center of Nis, Serbia, associated with the Medical Faculty, University of Nis. The study was undertaken according to the Helsinki Declaration and approved by the Institutional Review Board (IRB) of the Clinical Center in Nis, Serbia (number 9672/96). All subjects provided written informed consent. This study was designed as a prospective, open-label trial. Thirty-five patients (23 women and 12 men) were included in the study. The inclusion criteria were: age 35-65, all participants had DM type 2 and had been receiving oral antidiabetic drugs therapy for at least 6 months. The exclusion criteria were: vitamins, flavonoids, and fish oil supplement intake during the six-week period before the study and women that were on an oral contraceptive therapy during the study. The patients had been also receiving $150 \mathrm{ml}$ of polyphenol-rich chokeberry juice per day (three times a day for $50 \mathrm{ml}$ ) for a period of 3 months as part of their regular diet, together with their standard therapy. Biochemical parameters were measured at baseline, after 3 months of therapy with the chokeberry juice and after 3 months without the chokeberry juice therapy (6 months after the baseline), follow-up period. The measurements obtained after six months were used as the self-control, for the same group of patients, as they hadn't had the juice supplementation for the following three months (Calvo et al., 2016; Maitre et al., 2017; Skoczynska et al., 2007). During the whole study, standard patient's antidiabetic therapy was not changed.

Arterial blood pressure (BP) was measured three times in the right arm with a patient in the sitting position. Blood pressure, body weight, and height were measured using the standardized protocols on the same day when the blood and urine was taken. The body mass index (BMI) was calculated as weight $(\mathrm{kg}) /$ height $\left(\mathrm{m}^{2}\right)$.

\section{Polyphenol-rich chokeberry juice}

The chokeberry juice used in this study was donated from $\mathrm{Nu}$ trica d.o.o., Belgrade, Serbia. Fruits of the black chokeberry were collected from a plantation field in the mountain Suvobor (750 $\mathrm{m}$ a.s.1.), Serbia. The berries were handpicked in August 2011 and stored at $+5{ }^{\circ} \mathrm{C}$ for $24 \mathrm{~h}$. Fresh berries were crushed and squeezed in a wine horizontal screw press. The yield of the juice with respect to the weight of the fresh fruits was $73 \%$. The juice was filtered, pasteurized at $80{ }^{\circ} \mathrm{C}$ for $10 \mathrm{~min}$ and stored at $0{ }^{\circ} \mathrm{C}$ until the beginning of the study.

\section{Analysis of phenolic compounds}

The total concentration of phenols was estimated by FolinCiocalteu method as described by Waterman and Mole (1994), with slight modifications. $200 \mu \mathrm{l}$ of juices were added to $1 \mathrm{ml}$ of 1 : 10 diluted Folin-Ciocalteu reagent. After $4 \mathrm{~min}, 800 \mu \mathrm{l}$ of sodium carbonate $(75 \mathrm{~g} / \mathrm{l})$ was added. After $2 \mathrm{~h}$ of incubation at room temperature, the absorbance at $765 \mathrm{~nm}$ was measured. Gallic acid (0-100 mg/l) was used for calibration of a standard curve. The results were expressed as gallic acid equivalents per $\mathrm{g}$ of fresh weight (GAE/g FW). Triplicate measurements were taken and mean values were calculated.

Total anthocyanin content was examined according to the procedure described in European Pharmacopeia 6.0 (Council of Europe and European Pharmacopoeia Commission, 2007), with slight modifications. Briefly, $95 \mathrm{ml}$ of methanol were added to the juice (10 g equivalent of fresh berry), and mechanically stirred for $30 \mathrm{~min}$, then filtered into a $100 \mathrm{ml}$ volumetric flask. The filter was rinsed and diluted to $100 \mathrm{ml}$ with methanol. A 50-fold dilution of this solution in a 0.1 percent $\mathrm{v} / \mathrm{v}$ solution of hydrochloric acid in methanol was prepared. The absorbance of the solution was measured at $528 \mathrm{~nm}$, using a 0.1 percent $\mathrm{v} / \mathrm{v}$ solution of hydrochloric acid in methanol as the compensation liquid. The content of anthocyanins, expressed as cyanidin-3-O-glucoside chloride, was calculated from the expression: $\mathrm{A} \times 5000 / 718 \times \mathrm{m}(\mathrm{A}=$ absorbance at $528 \mathrm{~nm} ; 718$ = specific absorbance of cyanidin-3-O-glucoside chloride at $528 \mathrm{~nm} ; \mathrm{m}=$ mass of the substance to be examined in grams). Triplicate measurements were taken and mean values were calculated.

\section{Biochemical assays}

A detailed medical evaluation was performed at the baseline in order to evaluate whether the patients are eligible for the study. Venous blood samples and first-morning urine from patients were taken within the $24 \mathrm{~h}$ of checking the inclusion criteria and after an overnight fast of $12 \mathrm{~h}$. Standard analyses were performed on the same day. Hematological and routine 
biochemical parameters and biochemical markers were estimated by the Olympus AU 400 (Olympus, Tokyo, Japan) analyzer using the standard methods in a biochemical laboratory, such as the level of hemoglobin (HGB) and complete blood count parameters (UIBC, unsaturated iron binding capacity; TIBC, total iron binding capacity; Fe, iron concentration; Hgb, blood hemoglobin; WBC, white blood cell count; NEUT, neutrophils; LYMPH, lymphocytes; MONO, monocytes; EO, eosinophils; BASO, basophils; HCT, hematocrit; MCV, mean corpuscular volume; $\mathrm{MCH}$, mean corpuscular hemoglobin; $\mathrm{MCHC}$, mean corpuscular hemoglobin concentration; RDW-SD, RBC distribution width; PLT, platelet; MPV, mean platelet volume; $R B C$, red blood cell count), high sensitive C-reactive protein (hs-CRP), level of glucose (GLU), level of total cholesterol (CHOL), level of LDL-cholesterol (LDL), level of HDL-cholesterol (HDL), level of triglycerides (TG), urea level (URE), creatinine level (CRE), microalbuminuria and urine creatinine (CRE) level. The concentration of $\mathrm{HbA}_{1} \mathrm{C}$ was measured using an ion-exchange chromatography method (Bio Rad, California, US).

\section{Statistical analysis}

The sample size was calculated assuming that, through repeated measurements, we will receive a medium effect size, $\eta p^{2}=$ $0.06, \alpha=0.05$ and a study power of $80 \%$. Based on those parameters, the minimum sample size was 33 . The sample size calculation was performed in $G^{*}$ Power 3.1.9.2. As two main analyses, the Friedman test (i.e., a non-parametric test for testing the difference between several related samples /groups/) and the repeated measures analysis of variance (ANOVA) (which is used when the same parameter has been measured under different conditions on the same subjects) were conducted. The post hoc analysis was done (Wilcoxon signed-rank tests were conducted with a Bonferroni correction applied, resulting in a significance level set at $p<0.017)$ to evaluate differences between two time-points. Considering the small sample size, the analysis was conducted for all parameters in which a statistical significance was found for $p$-value $<0.1$ instead of $p$-value < 0.05 . The correlation analysis (Pearson correlation) was also conducted with the purpose of showing the strength of the association between the groups or variables. The analyses were performed using the SPSS statistical software package (ver. 20.0; Chicago, IL, USA). The data are shown as mean values \pm standard deviation (SD) and $p$-values indicated a statistical significance.

\section{Results}

Total phenolic content was $413.0 \pm 5.1 \mathrm{mg} \mathrm{GAE} / 100 \mathrm{~g}$ FW and the amount of total anthocyanins was $172.7 \pm 4.4 \mathrm{mg} / 100 \mathrm{~g}$.

The characteristics of the study population were determined at baseline (age, gender, body mass index, values of systolic and diastolic blood pressure, as well as the type of previous therapy for every participant) (Table 1).

The results of the analysis of biochemical parameters, body mass index and blood pressure values at baseline, after three months of the herbal drug therapy and after the next three months without the therapy (six months from the baseline), as well as the $p$-values are shown in Table 2.

The results of the analysis of blood count parameters values at baseline, after three months of the herbal drug therapy and after the next three months without the therapy (six months from the baseline), as well as the $p$-values are shown in Table 3.
Table 1. Characteristics of the study population at baseline

\begin{tabular}{lc}
\hline Variables & Mean \pm SD \\
\hline Age (years) & $56.3 \pm 6.8$ \\
DM duration (years) & $7.56 \pm 3.1$ \\
BMI $\left(\mathrm{kg} / \mathrm{m}^{2}\right)$ & $28.8 \pm 4.7$ \\
SBP $(\mathrm{mmHg})$ & $129.7 \pm 17.9$ \\
DBP (mmHg) & $82.8 \pm 9.4$ \\
Smokers \%(number) & $45.7(16)$ \\
ACE inhibitors therapy/sartans \%(number) & $14.2(5)$ \\
$\beta$-blockers therapy \%(number) & $11.4(4)$ \\
Combination therapy \%(number) & $40(14)$ \\
\hline
\end{tabular}

All values are presented as mean \pm SD. DM, diabetes mellitus type 2; BMI, body mass index; SBP, systolic blood pressure; DBP, diastolic blood pressure.

\section{Discussion}

The growing incidence of diabetes mellitus type 2, as a common public health problem in industrialized countries, could be reduced by the elimination of the risk factors leading to it. Cardiovascular diseases and diabetes mellitus accounts for $48 \%$ (18.2 million) and 3.5\% (1.33 million) respectively of the 38 million deaths due to NCDs in 2012 (WHO, 2016). The improvement of the dietary pattern in high-risk patients is considered to be effective protection and preventive measure for the reduction of disease development. Literature data demonstrated the association between the polyphenolic content in berries and their antidiabetic effects by achieving and maintaining glucose homeostasis (Edirisinghe and Burton-Freeman, 2016). Epidemiological studies indicate that anthocyanin consumption from different plant foods is associated with a reduced type 2 diabetes risk (Wedick et al., 2012).

Chokeberry juice is a rich source of polyphenol compounds that could be effective preventive and therapeutic agents in DM type 2 (Banjari et al., 2017; Simeonov et al., 2002; Yamane et al., 2017). Chokeberry juice supplementation in patients with DM type 2 could have an impact on the patient's health and well-being. The use of chokeberry with the standard oral antidiabetic drugs could prevent the development of diabetic complications such as diabetic nephropathy, as well as improve the hematological and lipid parameters in patients.

Our results demonstrated the decrease in the levels of all measured lipid parameters, as well as the fasting blood glucose levels and the concentration of $\mathrm{HbA}_{1} \mathrm{C}$, after three months of the supplementation with the chokeberry juice. Repeated measurements after the next three months without the supplementation showed again the increase in the levels of all these parameters. This could be the evidence of the therapy effects even though the statistical analysis authenticated a significant difference between the three-time measurements only in the concentration of LDL $(p<0.05)$ and $\mathrm{HbA}_{1} \mathrm{C}(p<0.05)$.

Some literature data indicate that aronia berries could be effective in the prevention of obesity, which is probably connected to their antioxidative activity (Kardum et al., 2014; Shin and Jung, 2016). Our results demonstrated a statistically significant difference in BMI measurements $(p<0.01)$, although the decrease in the values after the three-month therapy was slight. The significant change in systolic and diastolic blood 
Table 2. Mean values of biochemical parameters, body mass index and blood pressure at baseline, after three months of herbal drug therapy and after six months from the baseline

\begin{tabular}{|c|c|c|c|c|c|c|c|}
\hline & Baseline & After three months & After six months & $p$-value & $p_{1}$-value & $p_{2}$-value & $p_{3}$-value \\
\hline GLU (mmol/l) & $8(6.2-9.6)$ & $7.6(6.2-8.6)$ & $7.4(6.1-9)$ & 0.083 & 0.042 & 0.104 & 0.754 \\
\hline $\mathrm{HbA}_{1} \mathrm{C}(\mathrm{mmol} / \mathrm{mol})$ & $59.1 \pm 19$ & $55.1 \pm 14.7$ & $59.4 \pm 15.8$ & 0.012 & 0.193 & 0.417 & 0.004 \\
\hline $\mathrm{TC}(\mathrm{mmol} / \mathrm{l})$ & $6.1 \pm 1.3$ & $5.7 \pm 1.1$ & $6.1 \pm 1.5$ & 0.169 & & & \\
\hline LDL-C (mmol/l) & $3.7 \pm 1$ & $3.3 \pm 1$ & $3.8 \pm 1$ & 0.039 & 0.037 & 0.138 & 0.015 \\
\hline $\mathrm{HDL}-\mathrm{C}(\mathrm{mmol} / \mathrm{l})$ & $1.1(1-1.3)$ & $1.2(1-1.3)$ & $1.1(0.9-1.3)$ & 0.544 & & & \\
\hline $\mathrm{TG}(\mathrm{mmol} / \mathrm{l})$ & $2.2(1.5-3.3)$ & $1.9(1.6-3.1)$ & $2(6.1-8.9)$ & 0.823 & & & \\
\hline hs-CRP (mg/l) & $1.9(1.1-4.4)$ & $2.9(1.3-3.9)$ & $2.5(1.1-4.8)$ & 0.972 & & & \\
\hline $\mathrm{Hgb}(\mathrm{g} / \mathrm{l})$ & $136.7 \pm 12$ & $137.6 \pm 12.6$ & $140.8 \pm 12.7$ & 0.018 & 0.774 & 0.008 & 0.014 \\
\hline UREA (mmol/l) & $5(4.2-5.8)$ & $4.6(4.2-5.2)$ & $4.9(4.2-5.6)$ & 0.194 & & & \\
\hline CREAT $(\mu \mathrm{mol} / \mathrm{l})$ & $76.8 \pm 14.3$ & $74.7 \pm 13.9$ & $77.9 \pm 16.7$ & 0.035 & 0.087 & 0.259 & 0.013 \\
\hline Microalbuminuria (mg/l) & $8.3(5.9-17)$ & $6.5(3.9-14)$ & $8.3(4.4-13.6)$ & 0.829 & & & \\
\hline Urine CREAT (mmol/l) & $9.8(7-13.6)$ & $6.7(4.5-10.6)$ & $8.8(6.6-11.9)$ & 0.074 & 0.015 & 0.072 & 0.204 \\
\hline BMI $\left(\mathrm{kg} / \mathrm{m}^{2}\right)$ & $28.8 \pm 4.7$ & $28.4 \pm 4.5$ & $29 \pm 4.4$ & 0.006 & 0.021 & 0.257 & 0.002 \\
\hline SBP (mmHg) & $129.7 \pm 17.9$ & $128.7 \pm 17.1$ & $130.2 \pm 15.3$ & 0.596 & & & \\
\hline $\mathrm{DBP}(\mathrm{mmHg})$ & $82.8 \pm 9.4$ & $83 \pm 8.5$ & $82.7 \pm 8.7$ & 0.989 & & & \\
\hline
\end{tabular}

Values are presented as mean \pm SD or median (interquartile range); $p$-value $<0.05$ was considered significant and obtained using the Friedman test or ANOVA; $p_{1}, p_{2}$ and $p_{3}$-values $<0.017$ were considered significant (Bonferroni correction) and obtained using the Wilcoxon signed - rank tests (the post hock analysis); $p_{1}$-difference between the baseline and measurement after the three months; $p_{2}$-difference between the baseline and measurement after the six months; $p_{3}$-difference between the measurement after the three and six months from the baseline. GLU, blood glucose; $\mathrm{HbA}_{1} \mathrm{C}$, glycated hemoglobin; TC, total cholesterol; LDL-C, low-density lipoprotein cholesterol; HDL-C, high-density lipoprotein cholesterol; TG, triglycerides; hs-CRP, high sensitive C-reactive protein; UREA, blood urea; CREAT, blood creatinine; BMI, body mass index; SBP, systolic blood pressure; DBP, diastolic blood pressure.

Table 3. Mean values of blood count parameters at baseline, after three months of herbal drug therapy and after six months from the baseline

\begin{tabular}{|c|c|c|c|c|c|c|c|}
\hline & Baseline & Three months & Six months & $p$-value & $p_{1}$-value & $p_{2}$-value & $p_{3}$-value \\
\hline Transferrin (g/l) & $2.4 \pm 0.3$ & $2.5 \pm 0.2$ & $2.5 \pm 0.3$ & 0.140 & & & \\
\hline Ferritin $(\mu \mathrm{g} / \mathrm{l})$ & $67.6(32.5-93.3)$ & $43.9(26.1-100.9)$ & $55.7(25.2-100)$ & 0.063 & 0.003 & 0.037 & 0.376 \\
\hline $\mathrm{UIBC}(\mu \mathrm{mol} / \mathrm{l})$ & $43.6 \pm 9.6$ & $45.4 \pm 10.2$ & $44.4 \pm 9.8$ & 0.347 & & & \\
\hline TIBC $(\mu \mathrm{mol} / \mathrm{l})$ & $60.8 \pm 7$ & $61.1 \pm 6.5$ & $59.9 \pm 6.3$ & 0.328 & & & \\
\hline $\mathrm{Fe}(\mu \mathrm{mol} / \mathrm{l})$ & $16.4(13.4-20.6)$ & $15.1(10.3-18.7)$ & $14.1(11.6-18.4)$ & 0.114 & & & \\
\hline $\mathrm{Hgb}(\mathrm{g} / \mathrm{l})$ & $136.7 \pm 12$ & $137.6 \pm 12.6$ & $140.8 \pm 12.7$ & 0.018 & 0.774 & 0.008 & 0.014 \\
\hline WBC $\left(10^{9} / 1\right)$ & $7.2 \pm 1.5$ & $6.8 \pm 2.1$ & $6.9 \pm 1.5$ & 0.011 & 0.114 & 0.081 & 0.394 \\
\hline $\operatorname{NEUT}\left(10^{9} / 1\right)$ & $3.8(3.3-4.4)$ & $3.8(2.8-4.3)$ & $3.7(3.1-4.3)$ & 0.123 & & & \\
\hline LYMPH $\left(10^{9} / 1\right)$ & $2.5 \pm 0.8$ & $2.3 \pm 0.8$ & $2.4 \pm 0.7$ & 0.003 & 0.007 & 0.145 & 0.054 \\
\hline MONO $\left(10^{9} / 1\right)$ & $0.4 \pm 0.1$ & $0.4 \pm 0.1$ & $0.4 \pm 0.1$ & 0.395 & & & \\
\hline $\mathrm{EO}\left(10^{9} / 1\right)$ & $0.1(0.1-0.2)$ & $0.1(0.1-0.2)$ & $0.2(0.1-0.3)$ & 0.352 & & & \\
\hline $\operatorname{BASO}\left(10^{9} / 1\right)$ & $0.05(0.04-0.08)$ & $0.06(0.04-0.09)$ & $0.07(0.06-0.09)$ & 0.160 & & & \\
\hline HCT (1/l) & $0.4 \pm 0.03$ & $0.4 \pm 0.03$ & $0.4 \pm 0.04$ & 0.014 & 0.026 & 0.641 & 0.008 \\
\hline $\mathrm{MCV}$ (f) & $88.4 \pm 4.1$ & $87.5 \pm 3.8$ & $87.7 \pm 3.4$ & 0.026 & 0.017 & 0.062 & 0.602 \\
\hline $\mathrm{MCH}(\mathrm{pg})$ & $28.3 \pm 1.5$ & $28.8 \pm 1.6$ & $28.9 \pm 1.6$ & 0.001 & 0.013 & 0.000 & 0.871 \\
\hline $\mathrm{MCHC}(\mathrm{g} / \mathrm{l})$ & $321.2 \pm 10.3$ & $329.9 \pm 10.4$ & $321.1 \pm 51.3$ & 0.000 & 0.001 & 0.000 & 0.538 \\
\hline RDW-SD (f) & $13.1 \pm 1.3$ & $13 \pm 1.8$ & $12.6 \pm 0.9$ & 0.009 & 0.209 & 0.000 & 0.057 \\
\hline $\operatorname{PLT}\left(10^{9} / 1\right)$ & $264.4 \pm 50.9$ & $261.2 \pm 48.9$ & $265.1 \pm 49.7$ & 0.819 & & & \\
\hline MPV (fl) & $9.1 \pm 1.3$ & $10 \pm 1.5$ & $9.9 \pm 1.4$ & 0.005 & 0.000 & 0.001 & 0.539 \\
\hline $\mathrm{RBC}\left(10^{12} / 1\right)$ & $4.8 \pm 0.3$ & $4.7 \pm 0.3$ & $4.8 \pm 0.4$ & 0.040 & 0.254 & 0.242 & 0.015 \\
\hline \multicolumn{8}{|c|}{$\begin{array}{l}\text { Values are presented as mean } \pm \text { SD or median (interquartile range); } p \text {-value }<0.05 \text { was considered significant and obtained using the Friedman test or } \\
\text { ANOVA; } p_{1}, p_{2} \text { and } p_{3} \text {-values }<0.017 \text { were considered significant (Bonferroni correction) and obtained using the Wilcoxon signed-rank tests (the post } \\
\text { hock analysis); } p_{1} \text {-difference between the baseline and measurement after the three months; } p_{2} \text {-difference between the baseline and measurement } \\
\text { after the six months; } p_{3} \text {-difference between the measurement after the three and six months from the baseline. UIBC, unsaturated iron binding } \\
\text { capacity; TIBC, total iron binding capacity; Fe, iron concentration; Hgb, blood hemoglobin; WBC, white blood cell count; NEUT, neutrophils; } \\
\text { LYMPH, lymphocytes; MONO, monocytes; EO, eosinophils; BASO, basophils; HCT, hematocrit; MCV, mean corpuscular volume; MCH, mean } \\
\text { corpuscular hemoglobin; MCHC, mean corpuscular hemoglobin concentration; RDW-SD, RBC distribution width; PLT, platelet; MPV, mean platelet } \\
\text { volume; RBC, red blood cell count. }\end{array}$} \\
\hline
\end{tabular}


pressure in our study population after the three months of the chokeberry juice therapy, as well as after the follow-up period, was not established. The study population we included consisted of diabetic patients that had already received the standard antihypertensive therapy. On the other hand, it was noticed that blood pressure significantly decreased in the non-pharmacologically treated hypertensive subjects after four weeks of the chokeberry juice administration (Kardum et al., 2015).

In our study, the three-month therapy with chokeberry juice resulted in decreased levels of all measured lipid parameters, except for the concentration of plasma HDL cholesterol which was without change. After the next three months follow-up, the increase in the levels of these parameters was observed, which could be explained by the therapeutic effects of the chokeberry juice. A significant decrease was confirmed only in LDL concentration $(p<0.05)$. Other researches with animal models or humans also confirmed the improvement of lipid profile during the use of the chokeberry preparations (Borowska and Brzóska, 2016; Kardum et al., 2015; Sikora et al., 2012; Skoczynska et al., 2007; Valcheva-Kuzmanova et al., 2007b). A study of Skoczynska et al included the overweight or obese men with mild hypercholesterolemia and lasted 18 weeks with a daily chokeberry juice therapy of $150 \mathrm{ml}$ for six weeks, followed by six weeks without the juice therapy, and the next six weeks again with the therapy. It showed a decrease in the circulating levels of total and LDL cholesterol, as well as in serum triglycerides, glucose, homocysteine and fibrinogen levels and the increase in serum HDL cholesterol. Blood pressure values were also significantly decreased, while no difference was found in the levels of hs-CRP as the inflammatory marker (Skoczynska et al., 2007). In patients with metabolic syndrome, after eight weeks of the chokeberry extract administration (300 mg per day), a decrease in the levels of serum total and LDL cholesterol was observed, as well as in the triglyceride levels, but with no changes in HDL cholesterol levels, which is in accordance with our results (Sikora et al., 2012).

It is well known that inflammation processes and fat accumulation lead to damage in the glucose metabolism and insulin resistance which could be the cause of endothelial dysfunction and other inflammatory states (Cardillo et al., 2002; Hamdy et al., 2003). A significant positive correlation $(p<0.05)$ was found among the values of hs-CRP, which is the marker of inflammation and the parameters of glycemic control (blood glucose and $\mathrm{HbA}_{1} \mathrm{C}$ levels), as well as with some of the parameters that are related to the renal dysfunction (blood creatinine and urea, urine creatinine and microalbuminuria). There are many literature data that indicate a connection between an intensive glycemic control in patients with diabetes and the reduction of the incidence and progression of diabetic nephropathy, as well as other complications (Bi et al., 2012; King et al., 1999). It is well known that in diabetic patients, the glycation of various proteins increases. The increased levels of glycated hemoglobin $\left(\mathrm{HbA}_{1} \mathrm{C}\right)$, which is often used clinically as the standard chronic glycemic control indicator, could be associated with the development and progression of chronic diabetic complications (Cohen, 1998). The maintenance of $\mathrm{HbA}_{1} \mathrm{C}$ at a low level and the strict control of glycemia are two very important factors in the prevention of the development of diabetes complications, such as nephropathy (Umayahara et al., 2017). Our results showed a decrease in the levels of both, blood glucose and glycated hemoglobin, after the chokeberry juice supplementation, which could be of importance for the reduction of the incidence of diabetes complications. The decrease in the values of parameters related to the initial stage of the renal dysfunction (serum creatinine and urea, urine creatinine and microalbuminuria) after the juice intake confirmed the effects, even though only the decrease in the values of blood creatinine $(p<0.05)$ was statistically significant. After the follow-up period (three months without the juice supplementation), the increase of those parameters was noticed. Therefore, the decreases in the values of the parameters during the first three months were due to the chokeberry juice effects. The correlation analysis confirmed a strong positive correlation before and after the chokeberry juice therapy for all the parameters $(p<0.05)$. To the best of our knowledge, there is no literature information concerning the effectiveness of chokeberry products in renal disorders.

Literature data have shown the association of some hematological parameters, such as peripheral WBC count and type2 diabetes, micro and macro-vascular complications, coronary artery disease and stroke (Ford, 2002; Tong et al., 2004). It was demonstrated that the increase in differential cell counts, eosinophil, neutrophil, and monocyte, led to an increased incidence of coronary artery disease (Olivares et al., 1993; Prentice et al., 1982). WBC count could be an important predictor of the development and the progression of diabetic complications (Chung et al., 2005). A study that included the subjects with risk factors for type $2 \mathrm{DM}$ demonstrated the associations of HCT, Hgb, RBC, and WBC with $\beta$-cell dysfunction and glucose concentrations (Hanley et al., 2009). Our results showed a significant decrease in WBC $(p<0.05)$ and lymphocyte count $(p<0.01)$, while the decrease in other differential cell count was not significant. The significant changes were noticed in the levels of HCT, Hgb, MCV, MCH, MCHC, as well as in the RBC count $(p<0.05)$. Hemoglobin levels were increased after the three-month therapy; on the other hand, the level of blood Fe was lower after the chokeberry juice intake. The correlation analysis showed the strong positive correlation between the values at the baseline and after the three months of the juice therapy $(p<0.05)$. Changes in the values of clinically relevant hematological parameters could be the evidence of the chokeberry juice therapy effects. The decrease in the values of WBC and LYMPH count may indicate a reduction of inflammatory processes that influence the diabetes progression. Furthermore, it is necessary to conduct more comprehensive and detailed clinical investigations in the field of hematology in order to confirm those effects and show the association between the therapy and hematological parameters.

The presented results are in accordance with the earlier results that demonstrated the decrease in lipid and glucose parameters after supplementation with the chokeberry preparation. These effects could be related to the antioxidative and anti-inflammatory properties of the chokeberry preparations (Badescu et al., 2015; Broncel et al., 2010; Naruszewicz et al., 2007; Qin and Anderson, 2012; Rugina et al., 2015), considering the fact that the oxidative stress and inflammatory processes both contribute to the development of diabetes and metabolic syndrome, as well as of the cardiovascular disorders (Asmat et al., 2016; Naruszewicz et al., 2003, 2007; Rugina et al., 2011; Zhu et al., 2012). The review of the referential literature has shown that $A$. melanocarpa berries and the derived products could improve glucose metabolism by increasing the effectiveness of insulin (Qin and Anderson, 2012). Moreover, some of the compounds identified in the chokeberry juice, such as chlorogenic acid and cyanidin 3-O-arabinoside, could modulate the glucose and lipid metabolism (Braunlich et al., 2013; Meng et al., 2013).

Certainly, we should mention several limitations of our study. First of all, we analyzed patients with DM type 2 in three different measurement periods: at the baseline, after a three- 
month therapy with the chokeberry juice and after the next three months without the therapy (follow-up period). It is well known that the lack of a parallel control group, with the DM type 2 patients consuming the placebo juice at the same time, weakens the strength of our results. These diabetic patients were on their standard dietary regimen during the study, without sugar intake, as they always are. Making the placebo juice for the control group that is very similar to the chokeberry juice, with the same color and taste, was very difficult especially for those diabetic patients (any sugar intake is forbidden). Also, the patients had metabolic syndrome as well as some cardiovascular disorders, which made the placebo making harder. Considering all these circumstances, we decided to conduct the study with a longer follow-up period, where the subjects could be their own controls, without the interruption of their dietary pattern during the intervention and the follow-up period. Since this was a pilot study, we believe some useful information could be given, due to the different literature data regarding the potential chokeberry health benefits, even in the absence of a control group. Further research could be focused on the realization of the clinical investigation of chokeberry supplementation in patients with diabetes mellitus as well as other noncommunicable diseases. It should include a large number of participants; therefore, the results could be more relevant for therapy and clinical use.

\section{Conclusions}

In conclusion, the three-month daily consumption of the chokeberry juice could improve the health status in patients with type 2 diabetes mellitus, in combination with their standard therapy. We demonstrated the decrease in the values of glycemic and lipid parameters, as well as in the values of parameters that were related to the initial stage of the renal dysfunction and diabetic nephropathy. Moreover, we observed the influence of the juice intake on some hematological and inflammatory parameters. Nevertheless, it is necessary to conduct some further epidemiological, well-controlled studies to confirm these findings.

\section{Conflict of interests}

The authors have no conflict of interests to declare.

\section{Acknowledgements}

This study was supported by the Serbian Ministry of Education, Science and Technological Development (Grant no. III 46013 and III 41018) and by the Internal Project of the Faculty of Medicine, University of Nis, Serbia (No. 25). The authors are thankful to dr Aleksandra Ignjatovic, Faculty of Medicine, University of Nis for her expertise in statistical data processing and Mr. Aleksandar Jovanovic for his expertise in English.

\section{References}

Asmat U, Abad K, Ismail K (2016). Diabetes mellitus and oxidative stress - A concise review. Saudi Pharm J 24(5): 547-553. DOI: $10.1016 / j$.jsps.2015.03.013.

Badescu M, Badulescu O, Badescu L, Ciocoiu M (2015). Sambucus nigra and Aronia melanocarpa extracts on immune system disorders within diabetes mellitus. Pharm Biol 53(4): 533-539. DOI: 10.3109/13880209.2014.931441.

Banjari I, Misir A, Šavikin K, Jokic S, Molnar M, De Zoysa HK, et al. (2017). Antidiabetic effects of Aronia melanocarpa and its other therapeutic properties. Front Nutr 4: 53. DOI: 10.3389/ fnut.2017.00053.

Bi Y, Wang T, Xu M, Xu Y, Li M, Lu J, et al. (2012). Advanced research on risk factors of type 2 diabetes. Diabetes Metab Res Rev 28(Suppl. 2.): 32-39. DOI: 10.1002/dmrr.2352.

Bloom DE, Cafiero ET, Jané-Llopis E, Abrahams-Gessel S, Bloom LR, Fathima S, et al. (2011). The global economic burden of noncommunicable diseases. Geneva: World Economic Forum. Report No.: 080911.

Borowska S, Brzóska MM (2016). Chokeberries (Aronia melanocarpa) and their products as a possible means for the prevention and treatment of noncommunicable diseases and unfavorable health effects due to exposure to xenobiotics. Compr Rev Food Sci F 15(6): 982-1017. DOI: 10.1111/1541-4337.12221.

Braunlich M, Slimestad R, Wangensteen H, Brede C, Malterud KE, Barsett H (2013). Extracts, anthocyanins and procyanidins from Aronia melanocarpa as radical scavengers and enzyme inhibitors. Nutrients 5(3): 663-678. DOI: 10.3390/nu5030663.

Broncel M, Kozirog M, Duchnowicz P, Koter-Michalak M, Sikora J, Chojnowska-Jezierska J (2010). Aronia melanocarpa extract reduces blood pressure, serum endothelin, lipid, and oxidative stress marker levels in patients with metabolic syndrome. Med Sci Monit 16(1): CR28-34.

Calvo SM, Mehrotra A, Beelman BR, Nadkarni G, Wang L, Cai W, et al. (2016). A retrospective study in adults with metabolic syndrome: diabetic risk factor response to daily consumption of Agaricus bisporus (White Button Mushrooms). Plant Food Hum Nutr 71(3): 245-251. DOI: 10.1007/s11130-016-0552-7.

Cardillo C, Campia U, Bryant MB, Panza JA (2002). Increased activity of endogenous endothelin in patients with type II diabetes mellitus. Circulation 106(14): 1783-1787. DOI: 10.1161/01. cir.0000032260.01569.64.

Chung FM, Tsai JC, Chang DM, Shin SJ, Lee YJ (2005). Peripheral total and differential leukocyte count in diabetic nephropathy. Diabetes Care 28(7): 1710-1717. DOI: 10.2337/diacare.28.7.1710.

Cohen MP (1998). Nonenzymatic glycation: a central mechanism in diabetic microvasculopathy? J Diabet Complications 2(4): 214-217. DOI: 10.1016/s0891-6632(88)80012-6.

Council of Europe, European Pharmacopoeia Commission (2007). European Pharmacopoeia 6.0. 6th ed. Strasbourg: Council of Europe, pp. 1307-1308.

Edirisinghe I, Burton-Freeman B (2016). Anti-diabetic actions of Berry polyphenols - Review on proposed mechanisms of action. J Berry Res 6(2): 237-250. DOI: 10.3233/JBR-160137.

Ford ES (2002). Leukocyte count, erythrocyte sedimentation rate, and diabetes incidence in a national sample of US adults. Am J Epidemiol 155(1): 57-64. DOI: 10.1093/aje/155.1.57.

Hamdy O, Ledbury S, Mullooly C, Jarema C, Porter S, Ovalle K, et al. (2003). Lifestyle modification improves endothelial function in obese subjects with the insulin resistance syndrome. Diabetes Care 26(7): 2119-2125. DOI: 10.2337/diacare.26.7.2119.

Hanley AJ, Retnakaran R, Qi Y, Gerstein HC, Perkins B, Raboud J, et al. (2009). Association of hematological parameters with insulin resistance and $\beta$-Cell dysfunction in nondiabetic subjects. J. Clin Endocrinol Metab 94(10): 3824-3832. DOI: 10.1210/jc.20090719.

IDF Clinical Guidelines Task Force (2006). Global guideline for type 2 diabetes: recommendations for standard, comprehensive, and minimal care. Diabet Med 23(6): 579-593. DOI: 10.1111/j.14645491.2006.01918.x.

Kardum N, Milovanović B, Šavikin K, Zdunić G, Mutavdžin S, Gligorijević T, Spasić S (2015). Beneficial effects of polyphenol-rich chokeberry juice consumption on blood pressure level and lipid status in hypertensive subjects. J Med Food 18(11): 1231-1238. DOI: 10.1089/jmf.2014.0171.

Kardum N, Petrović-Oggiano G, Takic M, Glibetić N, Zec M, Debeljak-Martacic J, Konić-Ristić A (2014). Effects of glucomannan-enriched, aronia juice-based supplement on cellular antioxidant enzymes and membrane lipid status in subjects with abdominal obesity. Sci World J 2014: 869250. DOI: $10.1155 / 2014 / 869250$.

King P, Peacock I, Donnelly R (1999). The UK Prospective Diabetes Study (UKPDS): clinical and therapeutic implications 
for type 2 diabetes. Br J Clin Pharmacol 48(5): 643-648. DOI: 10.1046/j.1365-2125.1999.00092.x.

Kokotkiewicz A, Jaremicz Z, Luczkiewicz M (2010). Aronia plants: a review of traditional use, biological activities, and perspectives for modern medicine. J Med Food 13(2): 255-269. DOI: 10.1089/ jmf.2009.0062.

Krentz AJ, Bailey CJ (2005). Oral antidiabetic agents: current role in type 2 diabetes mellitus. Drugs 65(3): 385-411. DOI: 10.2165/00003495-200565030-00005.

Kris-Etherton PM, Hecker KD, Bonanome A, Coval SM, Binkoski EA, Hilpert KF, et al. (2002). Bioactive compounds in foods: their role in the prevention of cardiovascular disease and cancer. Am J Med 113(Suppl 9B): 71-88. DOI: 10.1016/s0002-9343(01)00995-0.

Kulling SE, Rawel HM (2008). Chokeberry (Aronia melanocarpa) a review on the characteristic components and potential health effects. Planta Med 74(13): 1625-1634. DOI: 10.1055/s-00281088306.

Maitre J, Guinhouya B, Darrieutort N, Paillard T (2017). Physical education in a thermal spa resort to maintain an active lifestyle at home: a one-year self-controlled follow-up pilot study. Evid Based Complement Alternat Med 2017(8): ID 1058419. DOI: 10.1155/2017/1058419.

Meng S, Cao J, Feng Q, Peng J, Hu Y (2013). Roles of chlorogenic acid on regulating glucose and lipids metabolism: a review. Evid Based Complement Alternat Med 2013: 801457. DOI: $10.1155 / 2013 / 801457$.

Narayan KM, Gregg EW, Fagot-Campagna A, Engelgau MM, Vinicor F (2000). Diabetes - a common, growing, serious, costly, and potentially preventable public health problem. Diabetes Res Clin Pract 50(Suppl. 2): S77-S84. DOI: 10.1016/s01688227(00)00183-2.

Naruszewicz M, Daniewski M, Łaniewska I, Pikto-Pietkiewicz W, Millo B, Zapolska-Downar D (2003). Effect of anthocyanins from chokeberry (Aronia melanocarpa) on blood pressure, inflammatory mediators and cell adhesion molecules in patients with a history of myocardial infarction (MI). Atheroscler Suppl 4(2): 143. DOI: 10.1016/S1567-5688(03)90615-5.

Naruszewicz M, Laniewska I, Millo B, Dłuzniewski M (2007). Combination therapy of statin with flavonoids rich extract from chokeberry fruits enhanced reduction in cardiovascular risk markers in patients after myocardial infarction (MI). Atherosclerosis 194(2): e179-e84. DOI: 10.1016/j. atherosclerosis.2006.12.032.

Olivares R, Ducimetiere P, Claude JR (1993). Monocyte count: a risk factor for coronary heart disease. Am J Epidemiol 137(1): 49-53. DOI: 10.1093/oxfordjournals.aje.a116601.

Prentice RL, Szatrowski TP, Fujikura T, Kato H, Mason MW, Hamilton HH (1982). Leukocyte counts and coronary heart disease in a Japanese cohort. Am J Epidemiol 116(3): 496-509. DOI: 10.1093/oxfordjournals.aje.a113434.

Qin B, Anderson RA (2012). An extract of chokeberry attenuates weight gain and modulates insulin, adipogenic and inflammatory signalling pathways in epididymal adipose tissue of rats fed a fructose-rich diet. Brit J Nutr 108(4): 581-587. DOI: 10.1017/ S000711451100599X.

Rugina D, Diaconeasa Z, Coman C, Bunea A, Socaciu C, Pintea A (2015). Chokeberry anthocyanin extract as pancreatic $\beta$-cell protectors in two models of induced oxidative stress. Oxid Med Cell Longev 2015: 429075. DOI: 10.1155/2015/429075.
Rugina D, Sconta Z, Pintea A, Bunea A, Socaciu C (2011). Protective effect of chokeberry anthocyanin-rich fraction at nanomolar concentrations against oxidative stress induced by high doses of glucose in pancreatic $\beta$-cells. Bulletin UASVM Cluj Napoca 68(1): 313-319. DOI: 10.15835/buasvmcn-vm:1:68:6792.

Shin JH, Jung JH (2016). Reduction of adipogenesis by chokeberry (Aronia melanocarpa) extract in 3T3-L1 preadipocytes. J Food Nutr Res 4: 210-215. DOI: 10.12691/jfnr-4-4-3.

Sikora J, Broncel M, Markowicz M, Chałubinski M, Wojdan K, Mikiciuk-Olasik E (2012). Short-term supplementation with Aronia melanocarpa extract improves platelet aggregation, clotting, and fibrinolysis in patients with metabolic syndrome. Eur J Nutr 51(5): 549-556. DOI: 10.1007/s00394-011-0238-8.

Simeonov SB, Botushanov NP, Karahanian EB, Pavlova MB, Husianitis HK, Troev DM (2002). Effects of Aronia melanocarpa juice as part of the dietary regimen in patients with diabetes mellitus. Folia Med (Plovdiv) 44(3): 20-23.

Skoczynska A, Jedrychowska I, Poreba R, Affelska-Jercha A, Turczyn B, Wojakowska A, Andrzejak R (2007). Influence of chokeberry juice on arterial blood pressure and lipid parameters in men with mild hypercholesterolemia. Pharmacol Rep 59(1): 177-182.

Tong PC, Lee KF, So WY, Ng MH, Chan WB, Lo MK, et al. (2004). White blood cell count is associated with macro and microvascular complications in Chinese patients with type 2 diabetes. Diabetes Care 27(1): 216-222. DOI: 10.2337/diacare.27.1.216.

Umayahara Y, Fujita Y, Watanabe H, Kasai N, Fujiki N, Hatazaki M, Koga M (2017). Association of glycated albumin to $\mathrm{HbA}_{1} \mathrm{c}$ ratio with diabetic retinopathy but not diabetic nephropathy in patients with type 2 diabetes. Clin Biochem 50(6): 270-273. DOI: 10.1016/j.clinbiochem.2016.11.032.

Valcheva-Kuzmanova S, Kuzmanov K, Tancheva S, Belcheva A (2007a). Hypoglycemic and hypolipidemic effects of Aronia melanocarpa fruit juice in streptozotocin-induced diabetic rats. Methods Find Exp Clin Pharmacol 29(2): 101-105. DOI: 10.1358/ mf.2007.29.2.1075349.

Valcheva-Kuzmanova S, Kuzmanov K, Mihova V, Krasnaliev I, Borisova P, Belcheva A (2007b). Antihyperlipidemic effect of Aronia melanocarpa fruit juice in rats fed a high-cholesterol diet. Plant Food Hum Nutr 62(1): 19-24. DOI: 10.1007/s11130-0060036-2.

Waterman P, Mole S (1994). Analysis of phenolic plant metabolites. Oxford: Blackwell Scientific Publication, pp.16.

Wedick NM, Pan A, Cassidy A, Rimm EB, Sampson L, Rosner B, et al. (2012). Dietary flavonoid intakes and risk of type 2 diabetes in US men and women. Am J Clin Nutr 95(4): 925-933. DOI: 10.3945/ ajcn.111.028894.

WHO (2016). Global status reports on noncommunicable diseases 2014. Geneva: WHO Press.

Yamane T, Kozuka M, Wada-Yoneta M, Sakamoto T, Nakagaki T, Nakano Y, Ohkubo I (2017). Aronia juice suppresses the elevation of postprandial blood glucose levels in adult healthy Japanese. Clin Nutr Exp 12: 20-26. DOI: 10.1016/j.yclnex.2017.01.002.

Zhu W, Jia Q, Wang Y, Zhang Y, Xia M (2012). The anthocyanin cyanidin-3-O- $\beta$-glucoside, a flavonoid, increases hepatic glutathione synthesis and protects hepatocytes against reactive oxygen species during hyperglycemia: involvement of cAMPPKA-dependent signalling pathway. Free Radic Biol Med 52(2): 314-327. DOI: 10.1016/j.freeradbiomed.2011.10.483. 